\title{
SOSIALE REKENINGKUNDE EN DIE TEORIE VAN FINANSIËLE REKENINGKUNDE
}

\author{
D.S. Lubbe \\ Dept. Rekeningkunde en hoof van die \\ Gencor Navorsingseenheid vir Ouditkunde \\ Universiteit van die Oranje-Vrystaat \\ BLOEMFONTEIN \\ en \\ Q. Vorster \\ Skool vir Rekenmeestersopleiding \\ Universiteit van Pretoria \\ PRETORIA
}

\begin{abstract}
In this article one of the approaches to social accounting, namely that of Ralph Estes (1976), is discussed briefly and elucidated by means of an example, and its most important advantages and disadvantuges are pointed out.

The theoretical concepts which have already crystallised with regard to social accounting are dealt with and contrasted with the theoretical concepts emerging from the framework of finuncial accounting.

An attempt has been made to determine whether Estes' approach is reconcilable with the theory of financial accounting, but this does not appear to be the case. This conclusion would probably apply to other approaches to social accounting as well.

It is concluded that this shortcoming should receive attention before the theoretical framework of accounting would be able to lay claim to general acceptance. Furthermore, the quest for meaningful methods for the disclosure of the social responsibility of undernakings offers the accounting profession the opportunity to consider fully some of the social problems of the world as a whole in co-operation with other experts.
\end{abstract}

\section{INLEIDING}

In hierdie artikel, die derde en laaste in die reeks oor sosiale rekeningkunde, word 'n enkele benadering, dié van Ralph Estes (1976), tot sosiale rekeningkunde bespreek. Daarna word die teoretiese begrippe van sosiale rekeningkunde teenoor dié van finansiële rekeningkunde gestel in 'n poging om vas te stel of die tradisionele finansieelrekeningkundige teoretiese model ook sosiale rekeningkunde, maar meer spesifiek, die 
Sosiale rekeningkunde en die teorie van finansiële rekeningkunde

voorstel van Estes kan akkommodeer. Laastens word enkele slotopmerkings en gevolgtrekkings gemaak ten opsigte van aspekte wat in die drie artikels bespreek is.

\section{ESTES SE BENADERING}

Ralph Estes se comprehensive social accounting model is die mees gevorderde van al die benaderings wat in hierdie reeks artikels toegelig word. Estes (1976:3) definieer sosiale rekeningkunde soos volg:

The measurement and reporting internal or external, of information concerning the impact of an entity and its activities on society.

Ter motivering van sy benadering maak Estes (1976:93) 'n vergelyking van die finansiële en sosiale rekeningkunde en meld hy die volgende:

The financial accounting model generally reflects the view of the entity looking out toward society; benefits (products and services) provided to society are thus indicated by the surrogate of revenues received, whereas costs are measured only by the entity's expenditures. Improved resource allocations could result from a different viewpoint, that of society looking toward the entity. Benefits to society would then be measured by the values or utilities act ually received by society (which may differ from the amount paid to the entity); while costs would reflect the fult detriments to society, and not only those for which the entity pays.

Die groot verskil tussen Estes se benadering en die vorige benaderings is dat die ander benaderings na 'n pragmatiese metode van sosiale rekeningkunde soek terwyl Estes ' $n$ veel meer filosofiese benadering aan die dag lê. Hy (1976:95) erken dan ook dat "(i)t should be emphasized that this model is somewhat idealistic and may not be presently practical for all firms". Estes stel hom ook op die koste-voordeelbenadering en hy (1976:92) definieer die twee terme soos volg:

- Social benefit: any benefit to society (or to any element of society), whether economic or 'nonecononic', internal or external. Thus social benefits include those benefits provided by an entity for which it is compensated as well as those 'external economies' and bargains for which no compensation (or inadequate compensation) is received.

- Social cost: any cost, sacrifice, or detriment to society (or to any element of society), whether economic or noneconomic, internal or external. Social costs include sacrifices for which compensation is made (such as human services used and paid for) as well as detriments not paid for (such as air pollution); any payments are treated separately as a benefit to socicty. (Traditionally the term social cost has been used to refer only to consumption or damage to society with no associated pecuniary cost to the offending or consuming entity, and thus not internalized by it, i.e. external diseconomies; the reader should be careful to note the broader, more inclusive meaning assigned here.)

Die volgende is Estes se voorgestelde social impact statement: 


\section{THE PROGRESSIVE COMPANY}

\section{SOCIAL IMPACT STATEMENT FOR THE YEAR ENDED DECEMBER 31, 19X1}

Social Benefits

Products and services provided

\$xxx

Payments to other elements of society

Employment provided (salaries and wages)

Payments for goods and other services

Taxes paid

Contributions

Dividends and interest paid

Loans and other payments

Additional direct employee benefits

Staff, equipment, and facility services

$$
\text { donated }
$$

Environmental improvements

Other benefits

Total Social Benefits

Social Costs

Goods and materials acquired

Buildings and equipment purchased

Labour and services used

Discrimination

In hiring (external)

In placement and promotion (internal)

Work-related injuries and illness

Public services and facilities used

Other resources used

Environmental damage

Terrain damage

Air pollution

Water pollution

Noise pollution

Solid waste

Visual and aesthetic pollution

Other environmental damage

Payments from other elements of society

Payments for goods and services provided

Additional capital investment

Loans

Other payments received

Other costs

Total Social Costs

$\underline{x x x}$

Social Surplus (Deficit) for the Year

Accumulated Surplus (Deficit) December 31, 19X0

\$xxx

$\underline{x x x}$ Accumulated Surplus (Deficit) December 31, 19X1 
Estes (1976:98) stel voor dat koste en voordele wat op toekomstige jare betrekking het, verdiskonteer moet word na die huidige waarde daarvan. Vir doeleindes hiervan gebruik hy die volgende formule:

$$
\begin{aligned}
& \text { "SS = } \sum_{i=1}^{n} \quad \sum_{t=1}^{\infty} \frac{B_{i}}{(1+r)^{t}}-\sum_{j=1}^{m} \sum_{t=1}^{\infty} \frac{C_{j}}{(1+r)^{t}} \\
& \text { where } \quad \text { SS }=\text { social surplus or deficit, } \\
& B_{i}=\text { the ith social benefit, } \\
& C_{j}=\text { the jth social cost, } \\
& r \quad=\text { an appropriate discount rate, } \\
& t \quad=\text { time period in which benefit or cost is expected to occur }
\end{aligned}
$$

Die benadering onder bespreking verskil van dié van Abt met betrekking tot die behandeling van die sosiale surplus. Abt argumenteer dat 'n sosiale surplus nie in die vorm van 'n 'reserwe' oor 'n aantal jare opgebou kan word nie. Estes daarteenoor maak wel in sy staat daarvoor voorsiening dat 'n 'sosiale reserwe' oor jare opgebou kan word. By die beoordeling van die twee uiteenlopende standpunte moet daar egter in gedagte gehou word dat Abt poog om 'n sosiale inkomstestaat en sosiale balansstaat op te stel terwyl Estes slegs een staat voorstel.

Die waarde van Estes se bydrae tot die ontwikkeling van sosiale rekeningkunde word waarskynlik eers besef wanneer daar 'n studie gemaak word van sy argumente aangaande die kwantifisering van die stellings volgens sy social impact statement. Dit val buite die bestek van hierdie artikel om al Estes se argumente aangaande die kwantifisering van sy stellings te bespreek. Slegs enkele daarvan word hier toegelig.

Soos met die meeste ander benaderings wat die koste-voordeelbenadering as grondslag het, lewer die kwantifisering van die sosiale voordele vir Estes nie wesenlike probleme nie. Sosiale koste is egter ' $n$ afdeling waar wesenlike vrae opduik wanneer oor die kwantifisering daarvan besin word. By die sosiale koste (goods and materials acquired) argumenteer Estes (1976:100 - 101) tereg dat die aankoopprys van goedere en materiaal nie voldoende is om hierdie stelling te kwantifiseer nie. Hy wys daarop dat die aard van die goedere en materiaal in ag geneem moet word. Sekere materiaal soos ru- 
olie is onvervangbaar terwyl hout (bome) wel oor die lang termyn vervang kan word en oeste (byvoorbeeld 'n koring-oes) binne 'n relatief kort tydperk.

Die sosiale koste (work-related injuries and illness) laat selfs moeiliker vrae as die vorige ontstaan. Estes (1976:136) meld dat baie persone sal wil argumenteer dat iets soos goeie gesondheid en die lewe van 'n persoon wat weens werkverwante beserings of siektes gesterf het, nie kwantifiseerbaar is nie. Hy toon egter aan dat ondernemings dikwels moet besin oor die beroepsveiligheid van werknemers en dat dit dus nie so vergesog is om ' $n$ 'waarde' op byvoorbeeld die veiligheid van werknemers en hul lewens te probeer plaas nie.

Die 'waarde' wat werknemers op hul eie lewens plaas, kan ook 'n maatstaf wees by die kwantifisering van die stelling onder bespreking. Estes (1976:140) gebruik die voorbeeld van 'n persoon wat bereid is om $\$ 300$ meer te betaal vir 'n voertuig toegerus met 'n lugkussing wat die risiko van dood in die geval van 'n botsing met 0,001 verlaag. Deur hierdie voertuig aan te koop, 'waardeer' die persoon sy lewe op $\$ 300000$ $(\$ 300 / 0,001)$. Die feit dat 'n mynwerker in Suid-Afrika wat aan 'n beroepsiekte soos myntering ly, geregtig is op vergoeding daarvoor, of die feit dat versekeraars die lewensverwagting van 'n versekerde probeer bepaal, is 'n bewys dat dit nie so vergesog is om siekte, beserings of selfs die lewe van 'n werknemer te probeer 'waardeer' nie.

Die meeste voor- en nadele wat by die ander koste-voordeelbenaderings genoem is, is ook van toepassing op Estes se benadering, en word dus nie herhaal nie.

\section{ESTES SE BENADERING EN DIE KONSEPTUELE RAAMWERK VAN FINANSIËLE REKENINGKUNDE}

\subsection{Inleiding}

Hoewel daar tans geen universeel-aanvaarde konseptuele raamwerk vir die rekeningkunde bestaan nie, het sekere fundamentele begrippe reeds 'n hoë mate van aanvaarding verwerf, onder meer na aanleiding van die SFAC-reeks van die Financial Accounting Standards Board, en die meer onlangse RE000 (1990), wat op 'n publikasie van die International Accounting Standards Committee gebaseer is. Ten opsigte van sosiale rekeningkunde in die besonder is daar egter ook enkele teoretiese begrippe gevestig, hoewel nie naastenby so omvangryk as vir finansiële rekeningkunde nie.

Daar word vervolgens kortliks ingegaan op die enkele begrippe en doelstellings wat reeds ten opsigte van sosiale rekeningkunde ontwikkel is, waarna dit met verbandhoudende begrippe in finansiële rekeningkunde vergelyk word. Laastens word die benade- 
ring van Estes getoets aan sekere van die begrippe van die raamwerk van finansiële rekeningkunde ten einde vas te stel in hoe 'n mate dit rekeningkundig-teoreties verantwoordbaar is.

\subsection{Oogmerke}

\subsubsection{Sosiale rekeningkunde}

Mobley (1970:766) verklaar dat daar veral in die beginstadium van die ontwikkeling van konsepte en doelstellings vir sosiale rekeningkunde vir 'n groot mate van buigsaamheid (flexibility) voorsiening gemaak moet word.

Stiner (1978:29) onderskei die volgende vyf doelstellings vir sosiale rekeningkunde:

1. constancy of construction from one time period to the next

2. consistently used from one time period to the next,

3. understandable to readers of the statements,

4. specific to the company's needs, and

5. objectively constructed.

Ramanathan (1976:520 - 523) onderskei die volgende drie doelstellings vir sosiale rekeningkunde:

Objective 1

An objective of corporate social accounting is to identify and measure the periodic net social contribution of an individual firm, which includes not only the costs and benefits internalized to the firm, but also those arising from externalities affecting different social segments.

Objective 2

An objective of corporate social accounting is to help determine whether an individual firm's strategies and practices which directly affect the relative resources and power status of individuals, communities, social segments and generations are consistent with widely shared social priorities on the one hand, and individuals' legitimate aspirations, on the other.

Objective 3

An objective of corporate social accounting is to make available in an optimal manner, to all social constituents, relevant information on a firm's goals, policies, programs, performance and contributions to social goals. Relevant information is that which provides for public accountability and also facilitates public decision making regarding social choices and social resource allocation. Optimality implies a cost/benefit-effective reporting strategy which also optimally balances potential information conflicts among the various social constituents of a firm. 


\section{2 .2 Finansiële rekeningkunde}

By die vertrekpunt van finansieel-rekeningkundige teorie om die oogmerk met finansiële state en die inligtingsbehoeftes van die gebruikers daarvan te bepaal, word lank reeds daaraan erkenning verleen dat finansiële state ook die resultate van die rentmeesterskap van die bestuur vir die bronne wat aan hulle toevertrou is, moet toon (RE000:14). Die Financial Accounting Standards Board het reeds in die vroeë sewentigerjare twaalf doelstellings geformuleer waaraan finansiële jaarstate moet voldoen (Stiner, 1978:30). Die laaste twee doelstellings handel oor die openbaarmaking van sosiale verantwoordelikheid en wel oor sosiale verantwoordelikheidsdoelstellings en -inligting wat die gemeenskap raak. Stiner $(1978: 30,31)$ wys egter daarop dat dit tans moontlik nie aanvaarbaar is om gesamentlike doelstellings vir finansiële en sosiale rekeningkunde te probeer formuleer nie.

Die American Accounting Association (1966:4) verklaar byvoorbeeld dat dit een van die doelstellings van die rekeningkunde is om inligting te verstrek ten einde die rentmeestersfunksie met betrekking tot hulpbronne te kan vervul, en om sosiale funksies en kontrole te vergemaklik. Belkaoui (1985:179) haal soos volg aan uit die Trueblood-verslag oor die doelwitte met finansiële state:

An objective of financial statements is to report on those activities of the enterprise affecting society which can be determined and described or measured and which are important to the role of the enterprise in its social environment.

Dit word voorts erken (RE000:21) dat finansiële state inligting mag vervat oor onder meer die risiko's en onsekerhede wat ' $n$ invloed het op die onderneming en oor hulpbronne en verpligtinge wat nie in die balansstaat verskyn nie.

Hoewel al hierdie uitsprake, met die moontlike uitsondering van die doelwit aangehaal uit die Trueblood-verslag hierbo, wesenlik ondernemingsgerig eerder as gemeenskapgerig is, word die vooruitsig vir sosiale verantwoording minstens nie daardeur in die wiele gery nie. Sosiale verantwoording sou waarskynlik binne hierdie uitgangspunte geakkommodeer kon word, maar dit sou tog nie volkome versoenbaar wees nie.

\subsection{Teoretiese begrippe van finansiële rekeningkunde}

Die mees prominente teoretiese begrippe van finansiële rekeningkunde is die kwalitatiewe eienskappe van finansiële state, naamlik daardie eienskappe wat dit vir gebruikers nuttig maak (RE000:24). Hierdie kwalitatiewe eienskappe omvat die eienskappe van verstaanbaarheid, toepaslikheid, betroubaarheid en vergelykbaarheid. Elkeen van hierdie eienskappe word vervolgens kortliks toegelig. 


\subsubsection{Verstaanbaainheid}

Hieronder word bedoel dat aangebode inligting deur 'n redelik ingeligte leser wat bereid is om dit met 'n redelike mate van toewyding te bestudeer, begryp moet word (SFAC2:40). Die Social impact statement van Estes sal waarskynlik hierdie vereiste bevredig.

\subsubsection{Toepaslikheid}

Toepaslike inligting beïnvloed die gebruiker se besluite deurdat dit gebeurtenisse bevestig wat reeds plaasgevind het, tans plaasvind of nog moet plaasvind of deur die korrigering van vorige besluite (SFAC2: 46). Toepaslike inligting bevat voorspellingswaarde deurdat gebruikers daarvan in staat gestel word om meer ingeligte besluite te neem, asook bevestigingswaarde, deurdat dit vroeëre besluite in perspektief plaas.

Dit is duidelik dat, globaal gesien, daar waarskynlik geen rede bestaan waarom die inligting vervat in die Social impact statement nie hierdie kriteria kan bevredig nie. In sommige opsigte mag hierdie staat groter toepaslikheidswaarde besit as die tradisionele inkomstestaat, en in kombinasie daarmee moontlik selfs meer.

Die toepaslikheid van inligting kan egter progressief deur tydsverloop verwater word. Tydigheid (RE000:43) plaas 'n beperking op toepaslikheid: hoe later inligting verstrek word, hoe minder toepaslik word dit. In hierdie opsig sal die Social impact statement waarskynlik neig om te faal, veral omdat die sosiale koste van bedrywighede meestal nie so tydig bepaalbaar is nie.

\subsubsection{Betroubaarheid}

Inligting waarop gebruikers kan staatmaak as 'n getroue weerspieëling van omstandighede of gebeurtenisse wat dit voorgee om te reflekteer, is betroubare inligting (SFAC 2:62). Dit impliseer onder meer dat inligting wat redelikerwys verwag kan word, wel verstrek is, en wel in ooreenstemming met die ekonomiese werklikheid daarvan en nie bloot ooreenkomstig regsvorm nie, asook dat dit onpartydig, volledig en omsigtig verantwoord is (RE000:33 - 38).

Onpartydigheid sal waarskynlik moeilik gehandhaaf kan word, veral aangesien die kwantifisering van items in die Social impact statement, soos reeds aangedui, problematies kan wees. Verder sal die graad van volledigheid wat behaal is uit die aard van die saak dikwels nie bepaalbaar wees nie, met die gevolg dat hierdie element 'n 
onbereikbare ideaal blyk te wees.

Terwyl 'n vertraging in die beskikbaarstelling van inligting soos reeds aangetoon, die toepaslikheid daarvan ondergrawe, kan dit egter die betroubaarheid daarvan versterk; hoe later inligting verstrek word, hoe betroubaarder is dit omdat dit immers die toets van die tyd deurstaan het.

\subsubsection{Vergelykbaarheid}

Finansiële state van dieselfde onderneming moet, indien dit van tydperk tot tydperk vergelyk word, gebruik kan word om die neiging in onder meer prestasie te bepaal. Ook moet finansiële state van verskillende ondernemings met mekaar vergelyk kan word om onder meer hulle relatiewe prestasie te beoordeel (RE000:39). Vergelykbaarheid veronderstel voorts dat rekeningkundige beleid, sowel as veranderinge daarin, verstrek sal word (RE000:40).

Hierdie kwalitatiewe eienskap van finansiële state sal, wat die vergelykbaarheid van die state van verskillende ondernemings betref, waarskynlik beperkend op sosiale verantwoording wees, omdat die sosiale koste van verskillende, veral andersoortige, ondernemings uit die aard van die saak heelwat van mekaar kan verskil. Daar kan geargumenteer word dat dit in finansiële rekeningkunde ook maar die geval tussen andersoortige ondernemings is, hoewel waarskynlik darem in geringer mate, sodat hierdie probleem, veral oor die langer termyn, waarskynlik nie 'n onoorkomelike struikelblok sal wees nie.

3.4 Teoretiese begrippe van sosiale rekeningkunde en die elemente van finansieelrekeningkundige state

Ramanathan (1976:520 - 523) onderskei die volgende ses teoretiese begrippe vir sosiale rekeningkunde:

Concepl 1

A social transaction represents a firm's utilization or delivery of a socio-environment resource which affects the absolute or relative interests of the firm's various social constituents and which is not processed through the market place.

Concept 2

Social overheads (returns) represent the sacrifice (benefit) to society from those resources consumed (added) by a firm as a result of its social transactions. In other words, social overheads are the measured value of a firm's negative externalities, and social returns is the measured value of its positive externalities. 


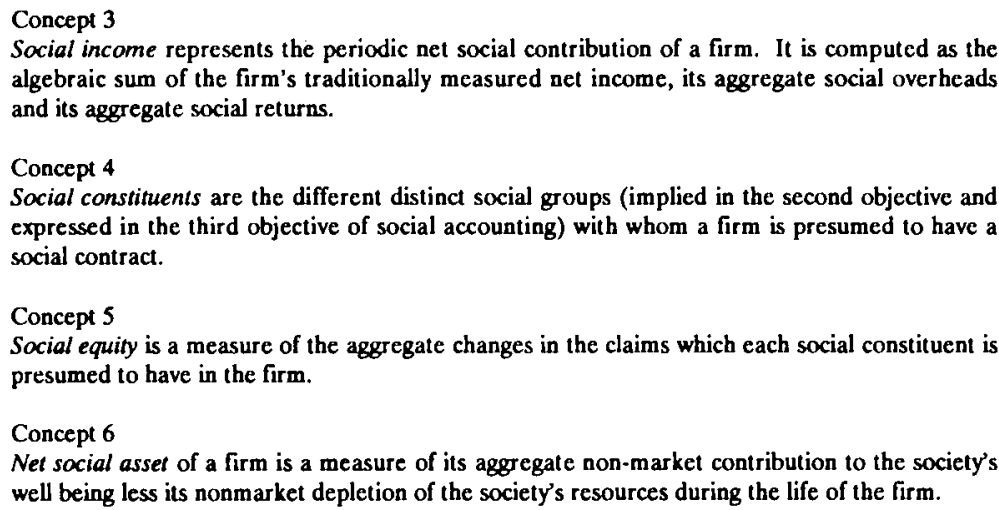

Die elemente van finansiële state wat in finansiële rekeningkunde erkenning geniet, is die volgende: bates, laste, ekwiteit, inkomste en uitgawes (RE000:49 en RE000:70). Elk van hierdie elemente word gedefinieer, en dit vorm wesenlik die inhoud van wat in die finansieel-rekeningkundige balansstaat en inkomstestaat opgeneem word. Die Social impact statement reflekteer aantoonbaar geen items wat as analogies aan konvensionele bates of laste beskou kan word nie en gevolglik word hierdie elemente, tesame met hulle residu, ekwiteit, nie hier behandel nie. Die ander elemente, inkomste en uitgawes, word egter in meer besonderhede beskou.

\section{Inkomste word beskryf as}

... toenames in ekonomiese voordele gedurende die rekenpligtige tydperk, in die vorm van toevloei van of toename in bates, of afname in laste wat 'n toename in ekwiteit tot gevolg het, uitgesonderd dié wat betrekking het op bydraes deur ekwiteitsdeelnemers (bv. aandeelhouers) (RE000:70).

\section{Uitgawes word beskryf as}

... afnames in ekonomiese voordele gedurende die rekenpligtige tydperk, in die vorm van die uitvloci van of afname in bates, of die aangaan van laste wat op die afname van ckwiteit uitloop uitgesonder die wat betrekking het op uitkerings aan ekwiteitsdeelnemers (bv. aandeelhouers) (RE000:70).

Hierdie omskrywings van inkomste en uitgawes is nie vir die doeleindes van sosiale verantwoording geskik of bruikbaar nie, aangesien dit inkomste en uitgawes omskryf in terme van bewegings in bates en laste wat, minstens volgens Estes se benadering, geen erkenning geniet nie. Ook in SFAC $6(1985: 78,80)$ word balansstaatposte as vertrekpunt vir die omskrywing van inkomste en uitgawes geneem. 
Belkaoui (1985:183) bespreek 'n ander benadering, die sogenaamde revenue/expense view, maar kom tot die gevolgtrekking dat dit minder suiwer is as dié gebaseer op bates en laste.

Wat sosiale verantwoording betref, is die elemente van finansieel-rekeningkundige verslaglewering dus nie van nut nie. Die teoretiese begrippe soos deur Ramanathan (1976:520 - 523) hierbo vir sosiale verantwoording geformuleer, of soortgelyke ander begrippe, sal as vertrekpunt moet dien.

\subsection{Die entiteitsbegrip}

In die vergelyking tussen die teoretiese begrippe van onderskeidelik die sosiale rekeningkunde en finansiële rekeningkunde, is daar in hierdie artikel, sover dit finansiële rekeningkunde betref, gesteun op die standpunte van die Suid-Afrikaanse Instituut van Geoktrooieerde Rekenmeesters en die Financial Accounting Standards Board oor die konseptuele raamwerk van rekeningkunde. Die entiteitsbegrip word nie as sodanig daarin omskryf nie, omdat dit as deel van die groter geheel van onderliggende teorie nie binne die konteks van daardie weergawes afsonderlike omskrywing verdien nie. Aangesien hierdie begrip egter waarskynlik die primêre verskil tussen finansiële rekeningkunde en sosiale rekeningkunde toelig, word dit vervolgens kortliks ontleed.

Die rekeningkundige entiteitsbegrip word deur Nikolai et al. (1982:15) soos volg omskryf:

From an accounting standpoint cach business is treated as a separate economic entity. An cntity is considered to be separate from its owners and from any other business. (Vergelyk ook dic separate entity concept volgens Miller, 1986:A.02.)

Sowel Hendriksen (1977:111) as Belkaoui (1981:102) verklaar dat die belang van die rekeningkundige entiteitsbegrip daarin geleë is dat dit die verwysingsveld van die finansiële rekeningkunde afbaken. Terselfdertyd word daardeur beperkinge geplaas op dit wat in finansiële verslae weerspieël moet word. Relevante inligting word so geopenbaar terwyl irrelevante inligting, wat slegs tot die vertroebeling van die inligtingsproses kan lei, uit die verslae geweer word.

Hendriksen (1977:111) verklaar dat die entiteit beskou kan word as daardie ekonomiese eenheid wat beheer uitoefen oor sy bronne, verantwoordelikheid aanvaar vir die aangaan van verpligtinge en oor die algemeen ekonomies aktief is. Daarvolgens kan 'n individu, vennootskap, maatskappy of groep maatskappye almal as rekeningkundige entiteite kwalifiseer, ongeag of die entiteit met 'n winsoogmerk of daarsonder optree. 
'n Alternatiewe beskouing van die rekeningkundige entiteit is dié van die American Accounting Association (1965:312) wat dit omskryf as enigiets wat deur die individu of 'n bepaalde groep met gemeenskaplike belange beskou word asof dit 'n afsonderlike en definieerbare bestaan as entiteit in die breedste sin sou hê. Hiervolgens is die belangrikste eienskap van die rekeningkundige entiteit daarin geleë dat dit, vanuit 'n bepaalde oogpunt beskou, 'n afsonderlike bestaan voer. Hierdie oogpunt kan 'n regsoogpunt, 'n sosiale oogpunt, 'n estetiese oogpunt, 'n politieke of 'n professionele oogpunt wees.

Hendriksen (1977:112) verklaar dat ofskoon albei beskouings tot dieselfde gevolgtrekking mag lei, die AAA se siening sou kon lei tot die keuse van ander inligting deurdat die sosiale aktiwiteite van die entiteit ook daardeur onder die soeklig kom, en gevolglik die openbaarmaking van die entiteit se gemeenskapsverantwoordelikheid noodsaak.

Dit wil egter voorkom of die begrippe in RE000 bespreek, nie op die AAA se besondere beskouing van die entiteitsbegrip gegrond is nie. Volgens RE000:70 verteenwoordig inkomste 'n toename in ekonomiese voordele. Vanuit die sosiale rekeningkunde sal daar, indien hierdie beskouing van die entiteitsbegrip vir die doeleindes van bogenoemde definisie buite rekening gelaat word, maklik bewys kan word dat baie sogenaamde 'ekonomiese voordele' vir die gemeenskap, omgewing, ensovoorts ook 'ekonomiese nadele' inhou.

\subsection{Ewewig tussen voordele en koste}

'n Deurlopende beperking op rapporteringsmaatstawwe is dat die koste verbonde aan openbaarmaking nie die voordele daarvan moet oorskry nie (RE000:44). In die geval van finansiële rekeningkunde, en waarskynlik ook in die geval van sosiale verantwoording, word die koste verbonde aan openbaarmaking hoofsaaklik gedra deur ander partye as dié wat die voordele daarvan geniet. Hierdie element sal dus geen groot bykomende komplikasie tot sosiale verantwoording voeg nie, maar sal in gedagte gehou moet word by die neerlè van riglyne ten opsigte van sosiale verantwoording.

\subsection{Gevolgtrekkings}

Ofskoon daar geen universeel aanvaarde raamwerk vir rekeningkunde bestaan nie, het sekere teoretiese begrippe van finansiële rekeningkunde pas maar eers wyer erkenning ontvang deur ' $n$ publikasie van die Internasionale Komitee vir Rekeningkundige Standaarde, en die plaaslike uitreiking daarvan as RE000. Hierdie begrippe het onder meer ten doel om die finansieel-rekeningkundige praktyk te orden en te standaardi- 
seer. Dit beoog nie om die teoretiese grondslae van sosiale verantwoording neer te le nie.

Sou die oogmerke van sosiale verantwoording egter versoen kon word met die huidige (moontlik voorlopige) raamwerk vir finansiële rekeningkunde, sou dit waarskynlik vir sowel die raamwerk as die beweging tot sosiale verantwoording as stimulus kon dien. Met die oog hierop is ondersoek ingestel na die mate waarin die belangrikste teoretiese begrippe van die raamwerk met een van die aangehaalde benaderings tot sosiale verantwoording, naamlik dié van Estes, versoen kan word. Dit is onwaarskynlik dat die gevolgtrekkings wesenlik sal verskil as enige van die ander benaderings vir dié doel gebruik sou word.

Die oogmerke met finansiële state verskil van dié van sosiale verantwoording, maar daar sal geen direkte konflik ontstaan nie, aangesien rentmeesterskap in breër verband deur albei gedien word. Tog sal die oogmerke met sosiale verantwoording meer pertinent gestel moet word. Dit word selfs as onaanvaarbaar beskou om gesamentlike doelstellings vir sowel finansiële as sosiale rekeningkunde te formuleer.

Ten opsigte van elke kwalitatiewe eienskap van finansiële state, met die moontlike uitsondering van dié van verstaanbaarheid, sal daar egter wel probleme wees. Omdat toepaslikheid deur tydigheid aan bande gelê word, kan sosiale verslae grootliks ontoepaslik wees, hoewel hierdie nadeel in 'n mate versag kan word deur groter betroubaarheid. Onpartydigheid, volledigheid en vergelykbaarheid sal beswaarlik haalbaar wees.

Die elemente wat in finansieel-rekeningkundige state vervat is, te wete bates, laste, ekwiteit, inkomste en uitgawes, is geheel en al onversoenbaar met die elemente van sosiale verantwoording. Laastens sal die voordele van sosiale verslae grootliks geniet word deur ander partye as dié wat vir die koste van die voorbereiding daarvan verantwoordelik is.

Dit wil dus voorkom asof finansieel-rekeningkundige teorie grootliks onversoenbaar is met sosiale verantwoording. Hierdie aspek sal aandag moet geniet voordat die raamwerk vir rekeningkunde op algehele aanvaarding aanspraak sal kan maak.

Die American Institute of Certified Public Accounts $(1977: 15,16)$ onderskryf ook die argument dat die ontwikkeling van 'n aanvaarbare metode vvir die sosiale rekeningkunde oor 'n lang termyn gaan plaasvind en verklaar dat "there is little possibility of the early achievement of the ideal system". In die lig hiervan onderskei die instituut tussen doelstellings vir 'n metode van sosiale rekeningkunde tydens die beginstadium en dié tydens die stadium wanneer 'n gesofistikeerde metode ontwikkel is. 


\section{SLOT}

Die hoofspreker tydens die nasionale kongres van die Kanadese Instituut van Geoktrooieerde Rekenmeesters in 1989 het daarop gewys hoe finansiële, rekeningkundige en ekonomiese sienings in die weg staan van die sosiale rekeningkunde. Hy (Luscombe, 1989:3) het aangedui dat albei die woorde ekonomie en ekologie afgelei is van die Griekse woord oikos, wat 'huis' beteken. Die ekonomie is volgens hom die bestuur van die huis terwyl die ekologie 'n studie daarvan is. Hy vervolg:

These should be companion fields, ... yet economies as it has come to dominate the world today makes no biological or ecological sense. The cost accounting in economics assumes that air, water and soil are infinite and free. They are what economists call 'externalities' to our calculation.

To an ecologist ... a standing forest performs numerous services: it prevents and retards flooding, retains large amounts of water, affects corrosion, ameliorates earthquake damage, retards fires, affects the weather and climate by transpiring massive amounts of water into the air, exchanges carbon dioxide for oxygen and supports a vast amount of genetic diversity in wildlife and plants. Yet the president of a major multinational logging company said last year, 'A tree only has value once it's cut down'.

That is an expression of the way economists think. A standing forest, in terms of economics, has no worth. It's only when you cut the tree down that it begins to return something to the cconomy. Don't tell me that economics makes sense if you don't account into it what forests do when they're still standing ...

In all fairness, the reason we don't account for these things is because, quite frankly, we don't know how. But we should, and we can.

Dit is duidelik dat daar nog baie onopgeloste vrae rondom die openbaarmaking van sosiale verantwoordelikheid bestaan. Nieteenstaande voorafgaande leemtes is dit duidelik dat die voorstanders van sosiale rekeningkunde nie 'n radikale ideologie probeer verkondig nie, maar opreg poog om die sosiale vraagstukke van die moderne wêreld op 'n realistiese wyse aan te pak. Die vordering wat wel gemaak is met die ontwikkeling van sosiale rekeningkunde en die sosiale oudit kan egter geensins geringgeskat word nie.

Die eise van 'n snel ontwikkelende wêreld bring dikwels mee dat individue en selfs professies so intens moet spesialiseer dat die vermoë om probleme (en die oplossing daarvan) binne 'n komplekse samelewingsmilieu raak te sien, verdwyn, en dat daar in die proses kontak met die werklikheid verloor word. Die soeke na sinvolle metodes vir die openbaarmaking van die sosiale verantwoordelikheid van ondernemings bied die rekenmeestersprofessie die geleentheid om weer 'n slag, in samewerking met verskeie ander dissiplines, uit die eng denkwyse van 'oorspesialisasie' te beweeg en om sommige sosiale vraagstukke van die wêreld as geheel te deurdink. 


\section{BIBLIOGRAFIE}

AMERICAN ACCOUNTING ASSOCLATION. 1966. A statement of basic accounting theory. Evaston : AAA.

AMERICAN ACCOUNTING ASSOCIATION. 1965. The realization concept. Accounting Review, $\mathrm{XL}(2): 312-322$.

AICPA. 1977. The measurement of corporate social performance. New York : American Institute of Certified Public Accountants.

BELKAOUI, A. 1985. Accounting theory. New York : Harcourt Brace Jovanovich

BELKAOUI, A. 1981. Accounting theory. New York : Harcourt Brace Jovanovich.

ESTES, R. 1976. Corporate Social Accounting. New York : John Wiley \& Sons.

HENDRIKSEN, Eldon S. 1977. Accounting theory. Homewood, Illinois : Richard D Irwin, Inc

LUSCOMBE, N. 1989. Accounting for what should be. CA Magazine, 122(11):3.

MILLER, M.A. 1986. Miller's comprehensive GAAP guide 1986. Orlando: HBJ.

MOBLEY, S.C. 1970. The challenges of socio-economic Accounting. The Accounting Review, XLV(4):762-768

NIKolai, LA., BAZLEY, J.D. \& STAllmaN, J.C. 1982. Principles of Accounting. Boston : Kent Publishing Company.

RAMANATHAN, K.V. 1976. Toward a theory of corporate Social Accounting. The Accounting Review, $\mathrm{LI}(3): 516-528$.

RE000 1990. Raamwerk vir die opstel en aanbieding van finansiële state. Johannesburg : Die SuidAfrikaanse Instituut van Geoktrooieerde Rekenmeesters.

SFAC2 1980. Qualitative characteristics of accounting information. Stamford : Financial Accounting Standards Board

SFAC6 1985. Elements of financial statements. Stamford : Financial Accounting Standards Board.

STINER, F.M. 1978. The attitudes of certified public accountants towards Social Accounting: A survey of national and Nebraska Opinion. Lincoln. (Ongepubliseerde proefskrif - The University of Nebraska.) 
